\title{
Special Effect of Ionic Liquids on Extraction of Diosgenin from Fenugreek (Trigonella foenum-graecum L.) by Ultrasonic Assistance
}

\section{Sahar Aminkara ${ }^{1}$, Abdolali Shojaeiyan ${ }^{1 *}$, Sajad Rashidi Monfaredb ${ }^{2}$ and Mahdi Ayyari ${ }^{1}$}

${ }^{1}$ Department of Horticultural Science, Faculty of Agriculture, Tarbiat Modares University, Tehran, Iran

${ }^{2}$ Department of Plant Biotechnology, Faculty of Agriculture, Tarbiat Modares University, Tehran, Iran

"Corresponding author: Shojaeiyan A, Department of Horticultural Science, Faculty of Agriculture, Tarbiat Modares University, Tehran, Iran, Tel: 09111383340; E-mail: shojaeiyan@modares.ac.ir

Received: April 28, 2018; Accepted: May 05, 2018; Published: May 10, 2018

Copyright: ( 2018 Aminkara S, et al. This is an open-access article distributed under the terms of the Creative Commons Attribution License, which permits unrestricted use, distribution, and reproduction in any medium, provided the original author and source are credited.

\begin{abstract}
An lonic Liquid Based Ultrasonic Assisted Extraction (ILUAE) was developed for profitable extraction of diosgenin from fenugreek leaves. Imidazolium based ionic liquids (ILs) differing in their anions was used as catalytic agent for extraction procedure in order to optimize the diosgenin extraction. Five ionic liquids, concentration of ILs, reaction time and solid to liquid ratio were optimized on one at the time procedure. The particle size was considered the same for all experiments [BMIM] $\mathrm{HSO}_{4}$ was selected as the best IL and in the final optimized condition, the extraction efficiency increased from 0.77 to $10.24\left(\mathrm{mg} \mathrm{g}^{-1} \mathrm{dw}\right)$ diosgenin. The method was also used to evaluate the concentration of diosgenin in different 13 accessions of Iranian fenugreek cultivated in the same place. The highest concentration of diosgenin with 20.2 and $20.1\left(\mathrm{mg} \mathrm{g}^{-1} \mathrm{dw}\right)$ were found in the Khash and Qaen accessions, respectively. Accession of Mashhad showed the lowest concentration with $6.8\left(\mathrm{mg} \mathrm{g}^{-1} \mathrm{dw}\right)$ diosgenin. After the reaction, the ILs from the media was also recovered using SPE column with more than $75 \%$ of yield. The result of this study showed that the optimized condition could extract the diosgenin almost five times more than the conventional method which could introduce fenugreek especially the best accession, as a new potential crop and source of diosgenin in the pharmaceutical industry.
\end{abstract}

Keywords: Dioscin; Ionic liquids; Iranian fenugreek; HPLC; Secondary metabolites; Steroidal saponin

\section{Introduction}

Natural products available at plant tissues provide a diverse and unique source of bioactive compounds for drug development. Despite significant progress in the pharmaceutical industry, substantial portion of the drugs in the last 25 years, obtained directly from natural products or their semi-synthetic modifications [1]. Saponins are a structurally diverse class of natural compounds which are widely distributed in the plant kingdom and involved in plant defense systems against pathogens. Chemically, they are related to triterpenic or steroidal glycosides that structurally consist of nonpolar aglycones coupled to one or more polar saccharide. The structure of saponins is the main factor of their surface-active characteristics [2]. Many kinds of saponins which isolated from different plant sources play a variety of physicochemical and biological functions such as foam production, sweetness and bitterness, antimicrobial and molluscicide that can be very practical in food industry, pharmaceutics, cosmetics and bioremediation [3].

Diosgenin, is a steroidal sapogenin and the product of acids or enzymes hydrolysis process of dioscin and protodioscin mostly from the plants (Figure 1) of the Dioscorea and trigonella species. This metabolite has considerable use as bioinsecticides. In fact, in the pharmaceutical industry, it wildly used as a precursor in the synthesis of some essential steroidal drugs such as cortisone, pregnenolone and progesterone [4]. Natural diosgenin mainly obtained from some wild species of Mexican yam (Dioscorea sp.). Although this process is timeconsuming and costly and also takes several years that tubers reach the proper size for profitable extraction of diosgenin [5]. With these reasons, fenugreek (Trigonella foenum-graecum) can be a suitable alternative for the natural source of diosgenin, because of its shorter growing cycle, lower production costs and more consistent of yield and quality.

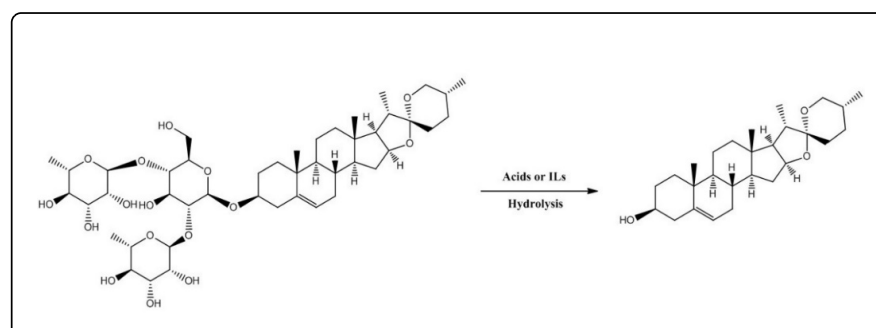

Figure 1: Dioscin hydrolysis process which catalyzed by inorganic acids or ILs aqueous solution.

Fenugreek ( $T$. foenum-graecum $L$.) is an annual, dicotyledonous plant, belonging to the family Fabaceae. Generally, the genus of Trigonella included 135 species which the most of them originated from southeastern Europe and Western Asia [6]. Fenugreek is one of the oldest medicinal plants which has many applications in traditional medicine to reduce blood glucose and cholesterol level [7]. The positive effect of fenugreek can be related to its bioactive compounds such as saponins, flavonoids, alkaloids, mucilaginous fiber, volatile oils and lysine-rich proteins (Mehrafarin). Profiling and discovery of different natural products from fenugreek including steroidal saponins is crucial to metabolomics and functional genomics [8]. Previous chemical investigations of fenugreek also led to the identification of 
Page 2 of 6

several new steroidal saponins [9]. It is reported that fenugreek contains a variety of steroidal saponins. Among them, dioscin as a significant water insoluble saponin, often used to obtain diosgenin through hydrolysis process.

The most common method of preparation and extraction of diosgenin from plant raw materials is hydrolysis by inorganic acids such as sulfuric and hydrochloric acid. Generally, these traditional techniques are not compatible with the current biological approaches because the traditional hydrolysis process catalyzed by inorganic acids suffers from energy inefficiency, environmental pollution, the risk of corrosion, the problem of acid recycling as well as carbonization of the product in high-temperature [10].

In recent years, ionic liquids are highly regarded as a new class of solvents due to their low vapor pressure and solubility power of various chemical compounds from minimal model molecules to complex metabolites in plants and organisms [11]. Actually, ionic liquids increase the dissolution of compounds with low solubility. Also, they can separate a molecule from others through their characteristics and chemical structure. These advantages are very interesting and important for the scientific community and industrial cycles associated with the natural functional resources [12].

Among them, the imidazolium based ILs has been studied extensively in the last decade because of their interesting physical and chemical properties. These ILs often have the useful ability to dissolve hydrophobic and hydrophilic solutes due to the amphiphilic nature of the cation (Veldhorst). Due to the disadvantages of traditional extraction methods and with regard to the efficiency and benefits of using ILs, they can be a convenient alternative for inorganic acids. Ultrasonic is a fast and reliable method which has been used successfully for extraction of steroidal saponins [13]. Furthermore, ultrasound-assisted extraction process can increase the efficiency of the catalyst and extraction, reduce solvent consumption which in recent years has been very popular $[10,14]$.

Since Iran is the one of the largest worldwide producer of fenugreek, the development of simple and efficient strategies for diosgenin extraction from this plant, could be a valuable contribution to the use of Iranian natural resources in green chemistry. In this study, we examined the catalytic ability of different ionic liquids for their hydrolysis activity, optimized the condition for the highest extraction of diosgenin and evaluated the recovery of ionic liquid after the extraction. To the best of our knowledge, this is the first report of using ILs and optimization to extract the diosgenin from fenugreek with interestingly highest yield.

\section{Materials and Methods}

\section{Materials}

The seeds of evaluated accessions including Arak, Shushtar, Yazd, Zanjan, Ardabil, Khash, Mashhad, Ardestan, Qaen, Shiraz, Damavand, Bushehr and Dezful were requested from gene bank and then cultivated in a sterilized mixture of soil: perlite (1:1) under greenhouse conditions at 25 and $18^{\circ} \mathrm{C}$ (day and night, respectively) and under a photoperiod of 16 and 8 hours (light and dark, respectively). Sampling was conducted in the first peak of flowering ( 45 days after planting).

\section{Chemical}

HPLC grade acetonitrile and all other solvents for extraction were purchased from Merck, (Darmstadt, Germany). Diosgenin standard and five kinds of ionic liquids including [BMIM] $\mathrm{HSO}_{4},[\mathrm{BMIM}] \mathrm{PF}_{6}$, $[\mathrm{BMIM}] \mathrm{BF}_{4},[\mathrm{BMIM}] \mathrm{Br}$ and $[\mathrm{BMIM}] \mathrm{Cl}$ with $96 \%$ purity were acquired from Sigma-Aldrich (Table 1). HPLC water was obtained from Millipore with SPE column.

\begin{tabular}{|l|l|l|l|l|}
\hline Ionic liquids & Anions & $\begin{array}{l}\text { Molecular } \\
\text { Formula }\end{array}$ & $\begin{array}{l}\text { Molecular } \\
\text { Weight }\end{array}$ & $\begin{array}{l}\text { State } \\
(\mathbf{2 5} \mathbf{C})\end{array}$ \\
\hline$[\mathrm{BMIM}] \mathrm{HSO}_{4}$ & $\mathrm{HSO}_{4}^{-}$ & $\mathrm{C}_{8} \mathrm{H}_{18} \mathrm{~N}_{2} \mathrm{O}_{4} \mathrm{~S}$ & 236.29 & Liquid \\
\hline$\left[{\mathrm{BMIM}] \mathrm{PF}_{6}}^{-}\right.$ & $\mathrm{PF}_{6}^{-}$ & $\mathrm{C}_{8} \mathrm{H}_{15} \mathrm{~F}_{8} \mathrm{~N}_{2} \mathrm{P}$ & 284.18 & Liquid \\
\hline$[\mathrm{BMIM}] \mathrm{BF}_{4}$ & $\mathrm{BF}_{4}^{-}$ & $\mathrm{C}_{8} \mathrm{H}_{15} \mathrm{BF}_{4} \mathrm{~N}_{2}$ & 226.02 & Liquid \\
\hline$[\mathrm{BMIM}] \mathrm{Br}$ & $\mathrm{Br}^{-}$ & $\mathrm{C}_{8} \mathrm{H}_{15} \mathrm{BrN}_{2}$ & 219.12 & Solid \\
\hline$[\mathrm{BMIM}] \mathrm{Cl}$ & $\mathrm{Cl}^{-}$ & $\mathrm{C}_{8} \mathrm{H}_{16} \mathrm{ClN}_{2}$ & 174.67 & Solid \\
\hline
\end{tabular}

Table 1: Basic information of five ionic liquids.

\section{Traditional method for diosgenin quantification}

Diosgenin extraction was performed as described previously with some modifications [15]. Briefly, $1.0 \mathrm{~g}$ of ground raw plant material was added into a tube with $20 \mathrm{~mL}$ of $96 \%$ ethanol and then subjected to ultrasonic extraction for $30 \mathrm{~min}$. ethanol is a solvent for prepration of total extract and extraction of Glycoside saponins such as Dioscin which in next step converts to Diosgenin during the hydrolysis process. Then, sulfuric acid $2 \mathrm{~N}(20 \mathrm{~mL})$ was added and hydrolyzed under reflux conditions at $100^{\circ} \mathrm{C}$ for $120 \mathrm{~min}$. The analyte was partitioned with $\mathrm{n}$ Hexane for three times. The combined n-Hexane solution was washed twice with $1 \mathrm{~mol} \mathrm{~L}^{-1}$ of $\mathrm{NaOH}$ solution, and then twice with distilled water. After dehydration with anhydrous sodium sulfate, the n-Hexane solution was concentrated to dryness under vacuum in a rotary evaporator. The extract was dissolved in acetonitrile and filtered with $0.22 \mu \mathrm{m}$ before injection [16]. All the experiment was performed with three replications.

\section{Preparation of diosgenin from $T$. foenum-graecum leaves}

Dried and ground raw plant material of $1.0 \mathrm{~g}$ was mixed with $20 \mathrm{ml}$ of ethanol $96 \%$ in a tube and then the suspensions were sonicated for 30 minutes. IL solutions were prepared by dissolving five kinds of 1buthyl-3-methyl imidazolium based ionic liquids in deionized water at the concentrations in the range of $0.01-0.05 \mathrm{~mol} \mathrm{~L}^{-1}$. After that, $20 \mathrm{ml}$ of ionic liquid solution was added to the mixture and hydrolyzed under reflux at $100^{\circ} \mathrm{C}$, the nature of ILs, concentration of selected ILs and the ratio of plant material to solvent $\left(\mathrm{g} \mathrm{ml}^{-1}\right)$ has been investigated. The obtained substance was dissolved with $5 \mathrm{~mL}$ acetonitrile, and then filtered through a $0.22 \mu \mathrm{m}$ microporous membrane prior to HPLC analysis.

\section{Analytical method}

Ultrasonic-CleanerXPS240-4L water baths (Sharpertek USA) were used in the extraction step. The generators of these ultrasonic water baths have frequency of $40 \mathrm{kHz}$. The content of diosgenin was evaluated by high performance liquid chromatography system (Waters, USA) with an SPDM20A PDA detector and a Strategy C18 column $(150 \mathrm{~mm} \times 3 \mathrm{~mm}, 5 \mu \mathrm{m})$. During this process, $20 \mu \mathrm{l}$ of the filtered 
extract injected into the column at room temperature. The mobile phase composition was acetonitrile: water $(90: 10, \mathrm{v} / \mathrm{v})$, at the flow rate of $0.4 \mathrm{ml} \mathrm{min}{ }^{-1}$, with ultraviolet (UV) detection at $210 \mathrm{~nm} \mathrm{[17].} \mathrm{The}$ peak identification was carried out by comparing its retention time with that of the corresponding peak in the standard diosgenin solution. All the experiments was performed with three replications. The content of diosgenin was determined based on the standard curve of diosgenin. The concentration of diosgenin was used to evaluate each extraction method.

\section{Results}

\section{Comparison of the performance of ionic liquids}

The acidity of IL solutions is considered as one of the most important factors in the hydrolysis of natural glycosides. As well, high solubility is required when ionic liquids are used as extraction solvents. In this study, we measured the $\mathrm{pH}$ of $[\mathrm{BMIM}] \mathrm{HSO}_{4},[\mathrm{BMIM}] \mathrm{PF}_{6}$, $[\mathrm{BMIM}] \mathrm{BF}_{4},[\mathrm{BMIM}] \mathrm{Br}$ and $[\mathrm{BMIM}] \mathrm{Cl}$ solutions via $\mathrm{pH}$ meter at $25^{\circ} \mathrm{C}$, which was $5.2,5.7,6.2,6.1$ and 6.4 , respectively. The effectiveness of selected ionic liquids compared under the same molar concentrations ( $0.04 \mathrm{~mol} \mathrm{~L}^{-1}$ aqueous solution), for $120 \mathrm{~min}$ and plant material to solvent $\left(\mathrm{g} \mathrm{ml}^{-1}\right)$ 15:1. The particle size was considered to be $>0.15 \mathrm{~mm}$ in all experiments. The results are presented in Figure 2. It was clear that the ionic liquids [BMIM] $\mathrm{HSO}_{4}$ could obtain the highest efficiency, which consists of the higher acidity and solubility for diosgenin, at the same time. Moreover, compared with other anions, $\left[\mathrm{SO}_{4}{ }^{-2}\right]$ and $\left[\mathrm{HSO}_{4}{ }^{-}\right]$could achieve a better performance [18]. $[\mathrm{BMIM}] \mathrm{HSO}_{4}$ has a sulfonic group which might cooperate with other anions to cause a stronger catalytic impact. Therefore, $[\mathrm{BMIM}] \mathrm{HSO}_{4}$ aqueous solution selected as the optimized solvent for hydrolysis of dioscin (Figure 2) and extraction of diosgenin.

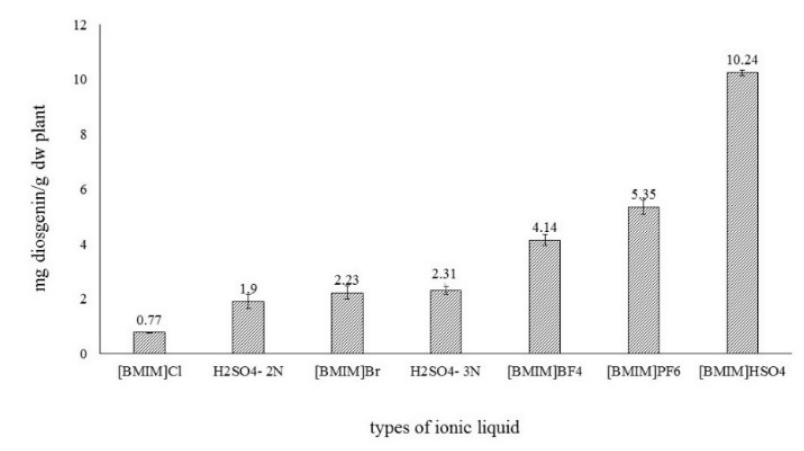

Figure 2: The effect of IL types on the yield of diosgenin and the comparison of ionic liquid assisted extraction with traditional extraction method.

\section{Effect of ionic liquid concentration on diosgenin yield}

Zeng et al. in their previous studies have shown that the concentration of ionic liquid in aqueous solution could have a significant effect on the efficiency of extraction. Based on this, the effect of different concentrations of $[\mathrm{BMIM}] \mathrm{HSO}_{4}$ aqueous solution (ranging from 0.01 to $0.05 \mathrm{~mol} \mathrm{~L}^{-1}$ ) on the extraction of diosgenin from T. foenum-graecum was studied. As showed in Figure 3A, extraction efficiency of diosgenin progressively increased over the concentration range from 0.01 to $0.04 \mathrm{~mol} \mathrm{~L}^{-1}$ and reduced after reaching the peak at $0.04 \mathrm{~mol} \mathrm{~L}^{-1}$. This could be explained by the fact that a large amount of micelles being formed with the addition of IL [19]. An IL-based surfactant could present a stronger interaction with diosgenin by hydrogen bonding and intermolecular forces, which could improve the relative extraction efficiency. On the other hand, the increased extraction capacity could not counteract the influence of increasing viscosity and diffusion resistance, which would make it more difficult for the IL solutions to penetrate into the herbal matrices. Thereby, the extraction efficiency decreased slightly [20]. Eventually, $0.04 \mathrm{~mol} \mathrm{~L}^{-1}$ was selected as the optimum concentration for further steps.

\section{Effect of reaction time on diosgenin yield}

The optimization of reaction time for diosgenin extraction was carried out at 60,120, 150 and 200 minutes. Other conditions including ionic liquid concentration and the ratio of plant material to solvent $\left(\mathrm{g} \mathrm{ml}^{-1}\right)$ was set at $0.04 \mathrm{~mol} \mathrm{~L}^{-1}$ and $1: 15$, respectively. Optimization process was performed with $[\mathrm{BMIM}] \mathrm{HSO}_{4}$ aqueous solution as the chosen ionic liquid. The results (Figure 3B) demonstrated that the highest efficiency of extraction obtained at 150 min and then gradually the efficiency reduced with increasing extraction time. This could be justified by the fact that the system reaches equilibrium at $150 \mathrm{~min}$. Thus, $150 \mathrm{~min}$ selected as the best reaction time for subsequent steps.

\section{Effect of the solid to liquid ratio on diosgenin yield}

The ratio of plant material to solvent $\left(\mathrm{g} \mathrm{ml}^{-1}\right)$, which is related to mass of plant and the volume of IL aqueous solution plays a major role in the extraction efficiency. Optimization experiments of solid to liquid ratio were performed in different ratios of 1:5, 1:10, 1:15, 1:20 and 1:25. Concentration of ILs and extraction time were applied according to the results of optimization. The results (Figure 3C) showed that the efficiency of extraction enhanced with the increase of plant material to solvent ratio and started to decline in the ratio of $1: 25$. Therefore, to make the best use of ionic liquids and enhance the efficiency of extraction, the ratio of $1: 20 \mathrm{~g} \mathrm{ml}^{-1}$ was considered as the optimal ratio.

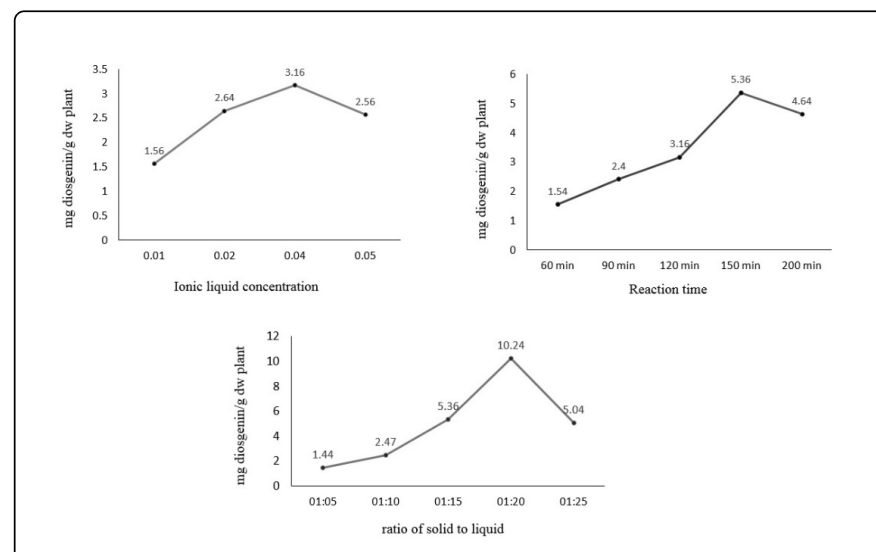

Figure 3: (A) The effect of the concentration of ionic liquid on the extraction efficiency (B) The effect of time on extraction efficiency (C) The effect of solid- liquid ratio on the extraction efficiency. 
Citation: Aminkara S, Shojaeiyan A, Monfaredb SR, Ayyari M (2018) Special Effect of lonic Liquids on Extraction of Diosgenin from Fenugreek (Trigonella foenum-graecum L.) by Ultrasonic Assistance. Nat Prod Chem Res 6: 322. doi:10.4172/2329-6836.1000322

Page 4 of 6

\section{Recovery of ionic liquid}

In the Eco-friendly pharmaceutical techniques, recovery of solvent (catalyst) always is important. In the study of ionic liquid recycling, the filtered extract can be used for one more time under optimized conditions (Figure 4). In the recycling process, residual of filtering, after hydrolysis process and phase out by n-Hexane, washed with distilled water. Then the cleaned residual were distilled under vacuum conditions in order to eliminate water. The mixture was diluted with ethanol $100 \%$ and filtered to eliminate water soluble impurities. The main separation process of residuals from the ionic liquid solution conducted by Solid Phase Extraction (SPE) column with VertiPakTM C18-HF SPE sorbent which was purchased from Vertical Chromatography Co.Ltd, in Bangkok, Thailand. The main objective of using the SPE column for recovery of ionic liquids was clean-up, concentrate and separation of diosgenin from ionic liquid aqueous solution. Satisfactory results were obtained with $75 \%$ of recovery and have been demonstrated in Figure 5. Extraction efficiency reduced only $25 \%$. The purity of the separated IL was $83 \%$.
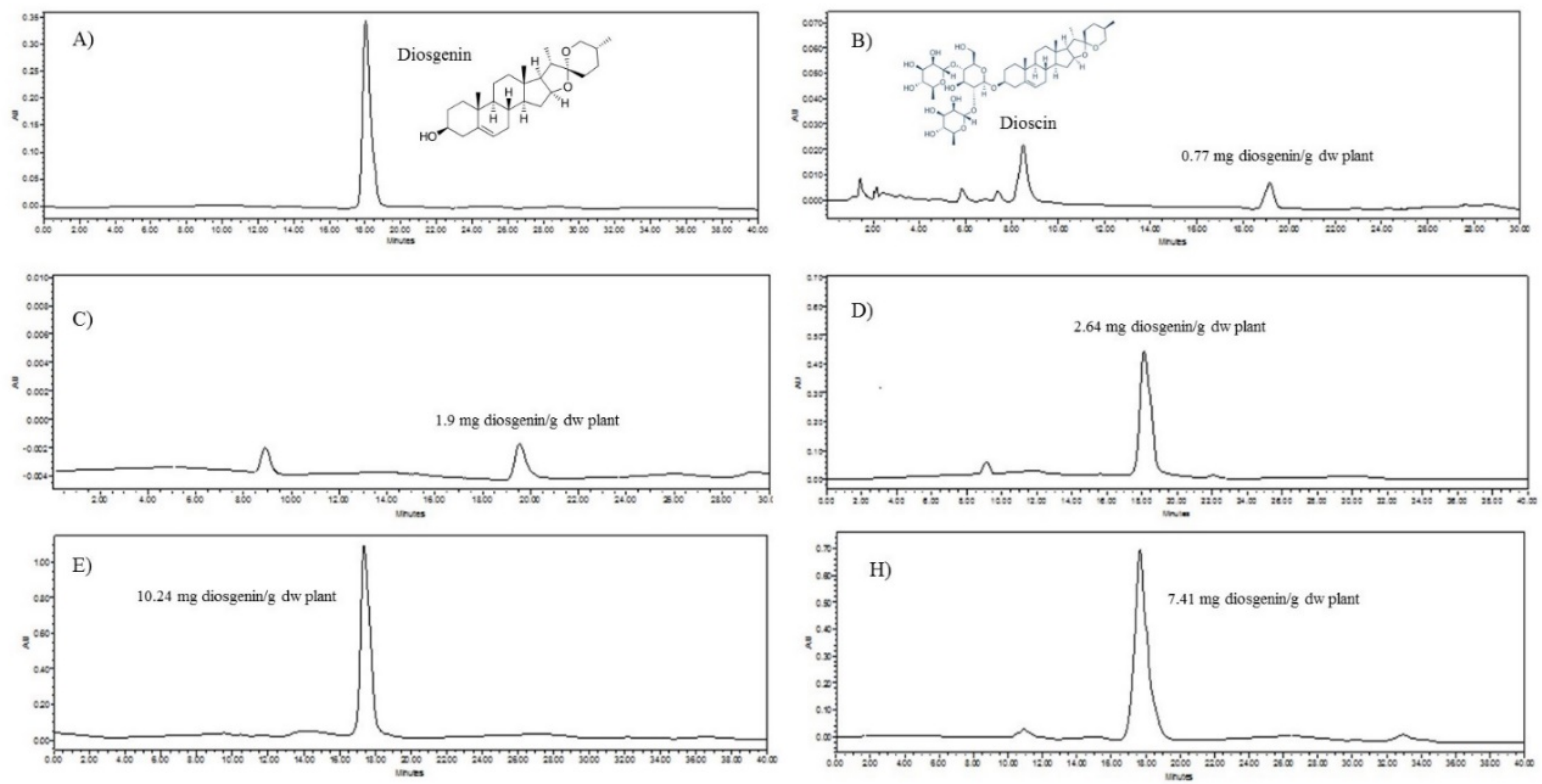

Figure 4: (A) HPLC profile of standard diosgenin $\left(1 \mathrm{mg} \mathrm{ml}^{-1}\right)$ Chromatographic separation of diosgenin with (B) [BMIM]Cl (C) sulfuric acid 2

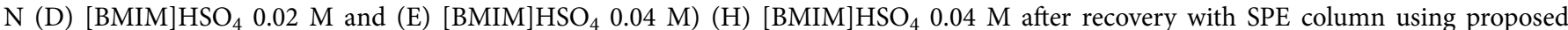
method at $210 \mathrm{~nm}$. Column: HPLC C18. Mobile phase: Acetonitrile: water (90:10, v/v). Flow rate: $0.4 \mathrm{ml} \mathrm{min}^{-1}$.

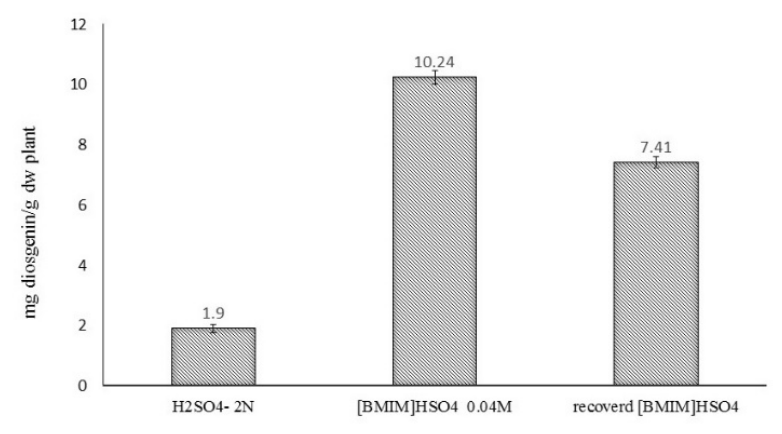

Figure 5: The effect of recycling on extraction efficiency.

\section{Diosgenin analysis of Iranian accessions}

Development of an efficient method for extraction and quantification of diosgenin from fenugreek leaves ( T. foenum-graecum $L$.) gives a chance for effective exploitation of this metabolite and provides a chance for further studies on pharmacological activity of steroidal saponins. Therefore, the ionic liquid extracts of 13 accessions of Iranian fenugreek validated with sensitive HPLC method. The highest concentrations of diosgenin 20.2 and $20.1\left(\mathrm{mg} \mathrm{g}^{-1} \mathrm{dw}\right.$ ) were found in the extracts obtained from Khash and Qaen, respectively. On the other hand, the accession of Mashhad showed the lowest concentration $\left(6.8 \mathrm{mg} \mathrm{g}^{-1} \mathrm{dw}\right)$ of diosgenin. The results showed the high diversity in the fenugreek samples and this method can be employed as a quantification method for determination of diosgenin in fenugreek. The results are shown in Figure 6. 


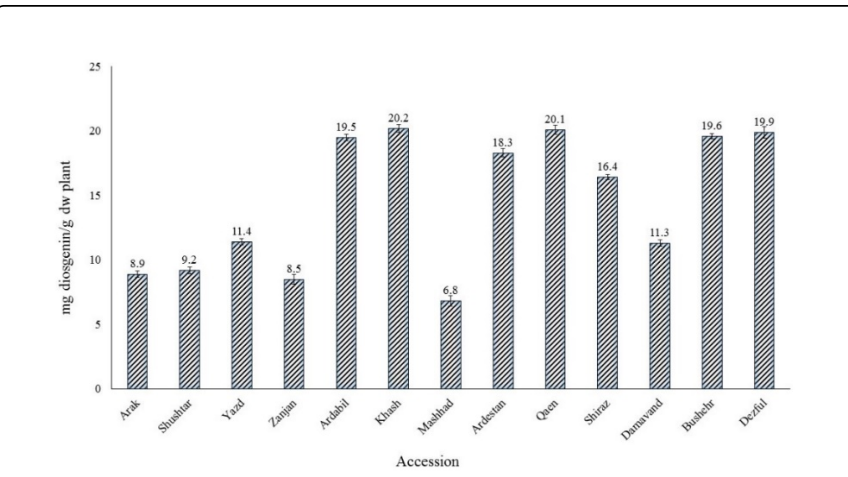

Figure 6: HPLC analysis of diosgenin of different accessions of Iranian Fenugreek.

\section{Conclusion}

According to the information reported in this article, it is clear that the use of ionic liquids could be very useful for enhancing the diosgenin extraction from fenugreek. Recently, ionic liquids have been successfully used for the extraction of fangchinoline and tetrandrine from Stephaniae tetrandrae [21]. In many dissolution processes, the interaction between the analyte and the solvent is a driving force in extraction process. Hydrogen-bonding, $\pi-\pi$, van der waals and columbic interactions have shown to effectively characterize the multiple complex interactions between the natural valuable products and the IL solvent [20]. As well, it has been shown that the IL performance in destroying the cell walls with the objective of reaching the desired compound for more solvation plays a key role, due to their low vapor pressure. Previous studies reported that the reorganization of cation and anion confined in sub-micrometer pores may affords more IL free volume and improves metabolite extraction. In many studies, samples treated with ILs provided lower specific surface for absorbance and could improve the efficiency of extraction [22].

Although, ionic liquids are widely used in polymer chemistry and chemical synthesis of organic materials, has received little attention to their use as a solvent extraction of natural compounds.

In this study, the extraction of diosgenin was undertaken with the use of ionic liquids as solvent. The results showed that the ILs can be applied as a dedicated solvent and significantly increase the efficiency of diosgenin extraction. This study proved that the Imidazolium-based ionic liquids solutions have a high potential for selective extraction of diosgenin from fenugreek leaves. $[\mathrm{BMIM}] \mathrm{HSO}_{4}$ was identified as the best for extraction of this metabolite. As indicated above, applying an aqueous solution of $[\mathrm{BMIM}] \mathrm{HSO}_{4}$ or other ionic liquids was appropriate and increases the extractive solvents for diosgenin. The best results were achieved with higher concentrations of [BMIM] $\mathrm{HSO}_{4}$ $\left(0.04 \mathrm{~mol} \mathrm{~L}^{-1}\right)$. Low density of ionic liquid aqueous solutions, at least in concentrations which studied, allows a better penetration of the solvent into the sample matrix and causes rapid mass transfer of metabolite in the liquid phase. The efficiency of extraction in different ionic liquids depends on the types of their anions and we found that fine extraction performance was accompanied by ionic liquids which had a high probability for hydrogen-bonding. Based on obtained results, we managed to develop an effective strategy for separating of diosgenin from fenugreek leaves by using ultrasonic-assisted dissolution. This strategy allowed not only isolating diosgenin in acceptable yields, but an easy recovery of the ionic liquid [BMIM] $\mathrm{HSO}_{4}$. Consequently, ionic liquids can be an affordable alternative of inorganic solvents for extraction of natural products such as diosgenin from plant organs.

\section{Acknowledgements}

We are grateful to the Research and technology council of Tarbiat Modares University for the financial support of this work especially for ionic liquids preparation.

\section{References}

1. Ressmann AK (2012) New aspects for biomass processing with ionic liquids: Towards the isolation of pharmaceutically active betulin. Green Chem 14: 940-944.

2. Güçlü-Üstündağ Ö, Mazza G (2007) Saponins: properties, applications and processing. Critic Rev Food Sci Nutri 47: 231-258.

3. Kalinowska M (2005) The formation of sugar chains in triterpenoid saponins and glycoalkaloids. Phytochem Rev 4: 237-257.

4. Fernandes P (2003) Microbial conversion of steroid compounds: recent developments. Enzym Microb Technol 32: 688-705.

5. Rosser A (1985) The day of the yam. Nursing Times 81: 47.

6. Martin E (2011) New chromosome numbers in the genus Trigonella L. (Fabaceae) from Turkey. African J Biotechnol 10: 116.

7. Mathur V, Mathur N (2005) Fenugreek and other lesser known legume galactomannan-polysaccharides: Scope for developments. J Sci Indus Res 64: 475.

8. Huhman DV, Sumner LW (2002) Metabolic profiling of saponins in Medicago sativa and Medicago truncatula using HPLC coupled to an electrospray ion-trap mass spectrometer. Phytochem 59: 347-360.

9. Zhang CL, Gao JM, Zhu W (2012) Steroidal saponins from the rhizomes and roots of Smilax scobinicaulis. Phytochem Lett 5: 49-52.

10. Takeda H (2002) Identification of rosmarinic acid as a novel antidepressive substance in the leaves of Perilla frutescens Britton var. acuta Kudo (Perillae Herba), Nihon shinkei seishin yakurigaku zasshi. Japanese J Psychopharmacol 22: 15-22.

11. Olivier-Bourbigou H, Magna L, Morvan D (2010) Ionic liquids and catalysis: Recent progress from knowledge to applications. Appl Catal A: General 373: 1-56.

12. Wu K (2009) Ionic liquid surfactant-mediated ultrasonic-assisted extraction coupled to HPLC: Application to analysis of tanshinones in Salvia miltiorrhiza bunge. J Separa Sci 32: 4220-4226.

13. Wang P (2014) Ionic liquid-based ultrasonic/microwave-assisted extraction of steroidal saponins from Dioscorea zingiberensis $\mathrm{CH}$ Wright. Tropical J Pharmaceu Res 13: 1339-1345.

14. Cheng P (2009) Pilot treatment of wastewater from Dioscorea zingiberensis $\mathrm{CH}$ Wright production by anaerobic digestion combined with a biological aerated filter. Biores Technol 100: 2918-2925.

15. Zhu Y, Huang W, Ni J (2010) A promising clean process for production of diosgenin from Dioscorea zingiberensis $\mathrm{CH}$ Wright. J Clean Prod 18: 242-247.

16. Li P (2011) Enhancement of diosgenin production in Dioscorea zingiberensis cell cultures by oligosaccharides from its endophytic fungus Fusarium oxysporum Dzf17. Molecu 16: 10631-10644.

17. Li P (2012) Quantitative determination of diosgenin in Dioscorea zingiberensis cell cultures by microplate-spectrophotometry and highperformance liquid chromatography. African J Pharm Pharmacol 6: 1186-1193.

18. Yan W (2013) New ionic liquid-based preparative method for diosgenin from Rhizoma dioscoreae nipponicae. Pharmacog Magazine 9: 250.

19. Zhou Y (2015) Special effect of ionic liquids on the extraction of flavonoid glycosides from Chrysanthemum morifolium Ramat by microwave assistance. Molecules 20: 7683-7699. 
Citation: Aminkara S, Shojaeiyan A, Monfaredb SR, Ayyari M (2018) Special Effect of lonic Liquids on Extraction of Diosgenin from Fenugreek (Trigonella foenum-graecum L.) by Ultrasonic Assistance. Nat Prod Chem Res 6: 322. doi:10.4172/2329-6836.1000322

Page 6 of 6

20. Passos H, Freire MG, Coutinho JA (2014) Ionic liquid solutions as extractive solvents for value-added compounds from biomass. Green Chem 16: 4786-4815.

21. Zhang L (2009) Ionic liquid-based ultrasound-assisted extraction of fangchinoline and tetrandrine from Stephaniae tetrandrae. J Separ Science 32: 3550-3554.
22. Wang J (2017) Effect of ionic liquid confinement on $\mathrm{CO}_{2}$ solubility and permeability characteristics, Greenhouse Gases. Sci Technol 7: 474-485. 